\title{
Maternal and Perinatal Outcome of Wilson Disease in Pregnancy: A 5-year Experience at a Tertiary Care Center
}

\author{
${ }^{1}$ KMN Vishnupriya, ${ }^{2}$ Chikkapura Nagaraja Rao Sheela, ${ }^{3}$ Mahalakshmi Thayumanasundaram
}

\begin{abstract}
Introduction: Wilson disease is a very rare inherited autosomal recessive disorder, with an incidence of 1 in 30,000 live births, associated with impaired copper metabolism leading to decreased biliary excretion and accumulation of copper in the liver and brain. Patients may be asymptomatic or might present with fulminant liver disease or neuropsychiatric illness. Untreated Wilson disease is related to infertility/subfertility/ recurrent pregnancy loss.
\end{abstract}

Aim: To study the maternal and perinatal outcomes of Wilson disease in pregnancy.

Materials and methods: It is a retrospective observational study carried out in the Department of Obstetrics and Gynecology, St. John's Medical College Hospital, Bengaluru, India, between November 2010 and November 2015. Five patients with Wilson disease were identified during the study period. Pregnancy outcome was good in all these five women who were on regular treatment.

Conclusion: Patients with Wilson disease who receive regular treatment and who remain asymptomatic and conceive normally have favorable pregnancy outcomes. They merit regular surveillance and active management in higher centers with multidisciplinary approach involving gastroenterologists, obstetricians, neurologists, and intensivists.

Keywords: D-penicillamine, Perinatal outcome, Pregnancy, Wilson disease.

How to cite this article: Vishnupriya KMN, Sheela CNR, Thayumanasundaram M. Maternal and Perinatal Outcome of Wilson Disease in Pregnancy: A 5-year Experience at a Tertiary Care Center. J South Asian Feder Obst Gynae 2017;9(4):318-322.

Source of support: Nil

Conflict of interest: None

Date of received: 8 October 2017

Date of acceptance: 3 December 2017

Date of publication: January 2018

\section{INTRODUCTION}

Wilson disease is a very rare autosomal recessive inherited disorder of copper homeostasis affecting 1:50,000

\footnotetext{
${ }^{1}$ Assistant Professor, ${ }^{2}$ Professor, ${ }^{3}$ Resident

1-3Department of Obstetrics and Gynecology, St. John's Medical College Hospital, Bengaluru, Karnataka, India

Corresponding Author: KMN Vishnupriya, 683, 11th A Main 5th Block, Jayanagar, Bengaluru 560041, Karnataka, India, Phone: +919945069750, e-mail: kmn_priyanil@yahoo.co.in
}

to $1: 100,000$ individuals. ${ }^{1}$ It is characterized by excess copper deposition due to a mutation in ATP7B on chromosome 13q14. The P-type adenosine triphosphatase is necessary for the export of copper from the hepatocyte. Thus, mutations in ATP7B lead to impaired biliary excretion and ceruloplasmin incorporation causing copper accumulation mainly in the liver and brain resulting in liver cirrhosis and nervous system manifestations, such as movement disorders and ataxia. ${ }^{2}$

Untreated Wilson disease results in oligomenorrhea, irregular menses, subfertility, and spontaneous miscarriage. This is probably due to hepatic dysfunction causing reversible hormonal changes. Free intrauterine copper derived from nonceruloplasmin-bound copper is excess in these patients. Also, diffusion of nonceruloplasminbound copper from plasma into tissues may affect ovarian follicular aromatase activity. ${ }^{3}$

Patients with Wilson disease who receive regular treatment and who remain asymptomatic and conceive normally have favorable pregnancy outcomes. We reported five cases of successful pregnancy outcomes in women with Wilson disease.

\section{CASE REPORTS}

\section{Case 1}

A 24-year-old primigravida presented to our antenatal clinic during the first trimester. She was diagnosed with Wilson disease (neuro and hepatic type) 1 year back when she was evaluated for ascites and tremors of upper limb (right $>$ left). The diagnosis was confirmed using 24-hour urinary copper levels and a dense broad Kayser-Fleischer ring (KF ring) on slit-lamp examination. She was started on T. penicillamine $250 \mathrm{mg}$ OD, zinc $50 \mathrm{mg}$ TID, and trihexyphenidyl hydrochloride $2 \mathrm{mg}$ TID, which was continued throughout pregnancy. Her younger sister was diagnosed with Wilson disease at screening. The patient conceived spontaneously and was on regular follow-up. An anomaly scan revealed no congenital anomalies. She was admitted at 33 weeks of gestation for evaluation of splenomegaly and portal hypertension, for which gastroenterology opinion was sought and was put on spironolactone and furosemide. During the admission, patient developed epistaxis, was found to have pancytopenia, and received 2 pint packed cell transfusion. The patient 
was under close surveillance throughout her pregnancy. At $38+3$ weeks, she had premature rupture of membranes (PROM) which spontaneously progressed and delivered vaginally a healthy girl baby of $2.5 \mathrm{~kg}$ with good APGAR scores. Four pint platelets were transfused when patient was in active labor as she had thrombocytopenia (platelet count 55,000/ $\mu \mathrm{L}$ ). Postpartum period was uneventful. She was followed up for the next 4 years. She developed symptomatic cholelithiasis, for which she underwent cholecystectomy 1 year after delivery. The baby was also followed up and has normal developmental milestones and cognitive development till date.

\section{Case 2}

A 22-year-old lady with previous two first trimester abortions presented to our antenatal clinic in the second trimester for regular antenatal follow-up. She was diagnosed with Wilson disease at the age of 17 years when she had chronic liver disease. She had an upper gastrointestinal bleed at 19 years of age and had undergone endoscopic variceal ligation. She developed postabortal psychosis and was put on quetiapine OD and haloperidol $\mathrm{OD}$, which she continued throughout pregnancy. She was on penicillamine $250 \mathrm{mg}$ 1-0-1, zinc $50 \mathrm{mg}$ TID, trihexyphenidyl 1-0-1, and pyridoxine hydrochloride 1-0-0. She presented to us at 37 weeks with PROM. She had moderate anemia and received 2 pint packed cells in labor. She underwent emergency cesarean delivery for fetal distress and delivered a healthy boy baby of $2.3 \mathrm{~kg}$ with good APGAR scores. Intra-op, she received 4 platelets as the platelet count was only $60,000 / \mu \mathrm{L}$. Postnatally, the patient had hematemesis and was diagnosed with upper gastrointestinal bleed and was shifted to intensive care unit (ICU) where she received bowel wash Q12H and somatostatin infusion for 48 hours. The patient eventually recovered and was discharged.

\section{Case 3}

A 19-year-old lady with a prior history of a missed abortion presented to our antenatal clinic at the end of second trimester for follow-up. She was diagnosed with Wilson disease at the age of 11 years on screening when her younger brother succumbed to Wilson disease. She was started on penicillamine $250 \mathrm{mg}$ OD. She conceived spontaneously and was asymptomatic at the time of presentation. T. penicillamine was continued at $250 \mathrm{mg}$ OD. She had an anomaly scan that showed no gross congenital anomalies. She was admitted at 29 weeks with leptospirosis and was treated with ceftriaxone injection for 7 days. She had respiratory tract infection at 32 weeks. At 34 weeks, the patient had preterm vaginal delivery and delivered a healthy boy baby of $2.02 \mathrm{~kg}$ with good
APGAR scores. Four pint platelets were transfused in active labor as her platelet count was only $40,000 / \mu \mathrm{L}$. The postpartum period was uneventful.

\section{Case 4}

A 28-year-old lady with an obstetric score of G3P1L0A1 presented at 36 weeks with decreased fetal movements. She was diagnosed with Wilson disease at 20 years of age when she was being evaluated for tremors. The patient was asymptomatic during her first pregnancy and underwent emergency cesarean delivery for nonprogress of labor, but baby expired after 5 months due to aspiration. The second was a missed abortion. In the present pregnancy, she was asymptomatic at the time of presentation. She was on T. penicillamine $250 \mathrm{mg}$ BD, pyridoxine $40 \mathrm{mg}$ BD, and zinc $100 \mathrm{mg}$ TID, which she continued. The dose of penicillamine was reduced to $250 \mathrm{mg}$ OD in the third trimester. Fetal monitoring was done at presentation and was found to be normal. She delivered a healthy girl baby of $3 \mathrm{~kg}$ with good APGAR scores at 38 weeks by elective cesarean and received 4 pint platelets as her platelet count was $54,000 / \mu \mathrm{L}$ and was discharged on the 5 th postoperative day. During follow-up, penicillamine dose was increased to $250 \mathrm{mg}$ BD.

\section{Case 5}

A 22-year-old lady with one previous abortion presented to us at 36 weeks of gestation in active labor. She was diagnosed with Wilson disease at 19 years of age when she developed splenomegaly and ascites. She was started on T. penicillamine $250 \mathrm{mg}$ OD and zinc $50 \mathrm{mg}$ TID, which she continued throughout her pregnancy. She delivered a healthy boy baby of $2.3 \mathrm{~kg}$ with good APGAR scores. The postnatal period was uneventful. She was continued on the same dose of medications and discharged.

\section{DISCUSSION}

Wilson disease is a rare autosomal recessive disorder involving a mutation in ATP7B gene, which is located on chromosome 13. Copper is essential for many cellular functions but free copper can produce irreversible cell damage. The ill-effects of free copper are prevented by ensuring the binding of free copper with ATP7B protein and ceruloplasmin. The ATP7B gene resides in the transGolgi network in hepatocytes. It mediates the incorporation of six copper molecules into apoceruloplasmin forming ceruloplasmin. ${ }^{4}$ The ATP7B is also redistributed to cytoplasmic vesicles where it transports excess copper across the hepatocyte apical membrane and gets excreted in bile. It also helps in transport of copper to the intended site and safe elimination of excess copper through biliary system. Mutation in ATP7B gene results in a defective 
protein that cannot help in transport of copper resulting in accumulation in hepatocytes. Hence, patients with this disease have ceruloplasmin deficiency. But, this alone is not diagnostic of Wilson disease as 5 to $15 \%$ patients may have normal or slightly reduced ceruloplasmin and 10 to $20 \%$ heterozygotes who are clinically asymptomatic have reduced ceruloplasmin. ${ }^{5,6}$

Although the basic defect of Wilson disease lies in the hepatobiliary system, the consequences of copper accumulation occur in a multisystemic fashion including brain, kidneys, and eyes. ${ }^{3}$ Accumulation of excess copper can adversely affect these tissues and can cause a spectrum of illness including cirrhosis, dyskinesias and tremors, KF ring around limbus, and renal tubular damage. ${ }^{5}$

Wilson disease may also lead to menstrual irregularities, which may be due to hepatotoxicity or copper accumulation in the uterus. ${ }^{7,8}$ Wilson disease may result in infertility, but all the patients in our study conceived spontaneously. ${ }^{9}$ Wilson disease in pregnancy has varied presentations and in our study, all patients had successful pregnancy outcomes.

The average age of patients for the onset of Wilson disease in our study is 11 to 23 years (Graph 1). The average age at which individuals conceived with Wilson disease in our study was 18 years compared with Ayesha's study, which was 22 years. ${ }^{1}$

Four out of five patients in our study had at least one first trimester abortion as compared with Ayesha et al's study, which had two abortions. In untreated Wilson disease, excess copper can accumulate in the uterus leading to recurrent miscarriage. ${ }^{1}$ This is similar to the contraceptive effects of copper-containing intrauterine devices, which act by causing deposition of copper in the endometrium leading to excess copper ions. ${ }^{10}$ It is believed that increased copper deposition in uterus prevents implantation of the fetus as free intrauterine copper derived from nonceruloplasmin-bound copper is excess

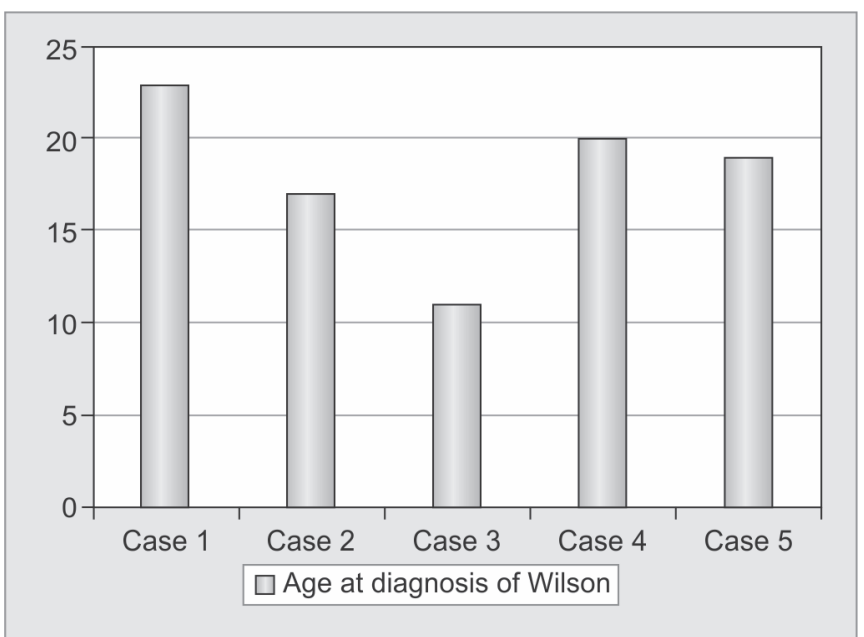

Graph 1: Mean age at diagnosis of Wilson disease in these patients. Other mechanisms like chronic liver disease, endocrine disorders, and anemia can also be a contributory cause. ${ }^{11}$

Our findings fully support the conclusions reached by Gibbs $\mathrm{K}$ and Walshe et al in their study, ${ }^{3}$ that if the patients have been adequately "decoppered" at the time of conception and those patients who continue penicillamine throughout pregnancy have successful pregnancy outcome. $^{3}$

After diagnosis, patients with Wilson disease should be treated for life. The accumulated copper must be removed using chelating agents. Therapy for Wilson disease includes D-penicillamine, trientine, zinc salts, and ammonium tetrathiomolybdate which are classified as pregnancy category $\mathrm{C}$ by the Food and Drug Administration. D-penicillamine acts by mobilizing tissue copper and increasing copper excretion in urine. Penicillamine produces a variety of adverse effects like acute sensitivity reactions with skin rash, fever, eosinophilia, thrombocytopenia, leukopenia, and lymphadenopathy in 20 to $30 \%$ of patients. ${ }^{12,13}$ The dose of penicillamine should be reduced to $250 \mathrm{mg}$ / day, 1 to 6 weeks prior to cesarean delivery in order to prevent delayed wound healing. 5,6 There have been some reported congenital malformations with use of D-penicillamine including fragile blood vessels, collagen vascular disease, low-set ears, and micrognathia. ${ }^{3}$

There was no evidence of teratogenicity in all our five patients treated with D-penicillamine. Case 1 was followed up for 4 years and the baby is normal till date. Even in Walshe study, there was no teratogenicity noted.

Trientine is a copper chelating agent with a mechanism of action similar to penicillamine, which is used as an alternative when patients develop an allergic reaction to penicillamine. It should be taken on an empty stomach and the usual daily dose is 750 to $2000 \mathrm{mg}$ in three divided doses. ${ }^{6}$ This is a very effective alternative and no adverse fetomaternal outcomes have been reported. ${ }^{14,15}$

The use of zinc in the treatment of Wilson disease has gradually assumed an increasingly important role. ${ }^{16}$ Zinc acts by interfering with the absorption of copper from the gastrointestinal tract via induction of metallothionein formation in intestinal enterocytes. ${ }^{2,17}$ This prevents the serosal transfer of copper into blood. ${ }^{18}$ In our case series, 4 out of 5 patients were treated with zinc sulfate and no congenital anomaly has been reported (Graph 2). Brewer ${ }^{6}$ reported that 24 out of 26 patients had a normal infant with the use of zinc sulfate, one infant had a congenital heart defect, and one had microcephaly. The usual dosage regimen is $50 \mathrm{mg}$ of elemental zinc three times daily (zinc sulfate tablets contain $220 \mathrm{mg}$ zinc sulfate equivalent to $50 \mathrm{mg}$ of elemental zinc). ${ }^{2}$

In 40 to $50 \%$ of individuals with Wilson disease, hepatic dysfunction is the initial clinical manifestation, 6,12 
Maternal and Perinatal Outcome of Wilson Disease in Pregnancy

Table 1: Comparison of three studies

\begin{tabular}{llll}
\hline Studies & Malik et al $^{1}$ & Gibbs and Walshe $^{3}$ & Our study \\
\hline No. of patients & 4 & 10 & 5 \\
Mean age (years) & 22.5 & 14 & 18 \\
Mean duration of therapy at & 4.75 & 10.5 & 5.2
\end{tabular}
conception (years)

Symptoms at diagnosis

Morbidity
Neuropsychiatric $(75 \%) /$ hepatic

Preeclampsia (75\%)/ Thrombocytopenia (50\%)
Presymptomatic/neurological $(40.25 \%) /$ hepatic $(20 \%)$

Preeclampsia (20\%)
Hepatic $(60 \%) /$ neuropsychiatric

Thrombocytopenia (75\%), 1 ICU admission (esophageal varices)

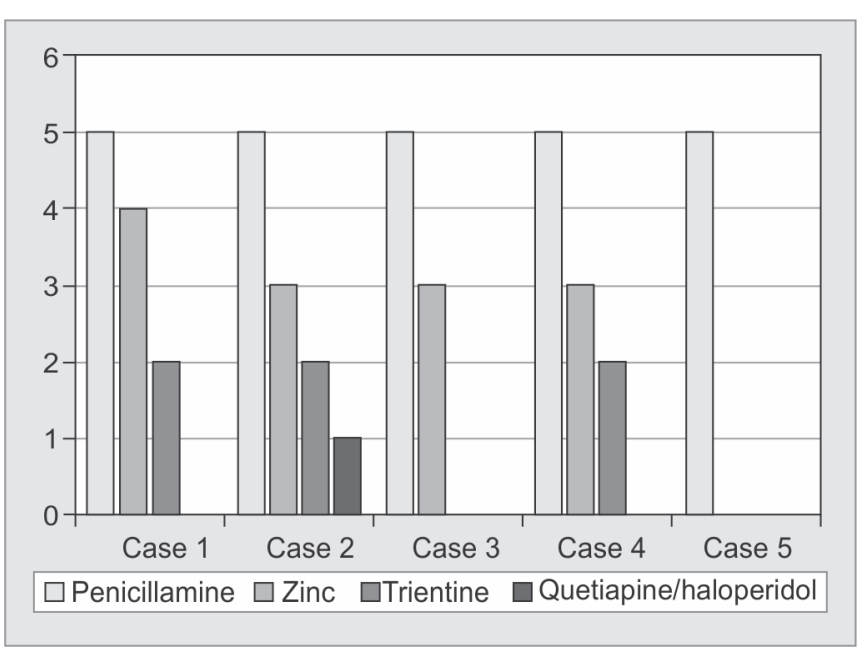

Graph 2: Drugs used for treatment of Wilson disease in pregnancy

similar to our study where $60 \%$ patients were diagnosed with hepatic disease.

Malik et $\mathrm{al}^{1}$ reported the incidence of preeclampsia in 3 out of 4 patients. It may be hypothesized that this may be due to underlying disease or is related to anticopper therapy used during pregnancy. ${ }^{21}$ There was no preeclampsia in our study.

These patients are also at risk of placental abruption and thrombocytopenia and deranged coagulation. ${ }^{19,20}$ Thrombocytopenia was seen in 4 out of 5 patients in our study. This might be due to drug-induced toxicity. ${ }^{3} \mathrm{Con}$ tinuous penicillamine intake can lead to mild or moderate thrombocytopenia. In Malik et al's study, two out of four cases had thrombocytopenia. All patients were on penicillamine therapy. These major findings of our study are compared with Ayesha Malik et al study ${ }^{1}$ and Walshe et al study, ${ }^{3}$ presented in Table 1. Fetal growth restriction was noted in a study by Bhattacharyya et al. ${ }^{21}$

The sudden omission of chelating agents in the antenatal period by the mother may be from apprehension of fetal affection or due to severe gastric irritation. Failure to comply with therapy has led to the significant progression of liver disease and liver failure in 1 to 12 months following discontinuation of treatment, resulting in death or necessitating liver transplantation. ${ }^{22}$ Intense counseling in the preconceptional period and stringent surveillance can avoid such a situation.
As Wilson disease is an autosomal recessive disorder, the baby remains a carrier. If the father is by chance heterozygous, the chance of fetus getting affected is $50 \% .{ }^{22}$ When the parental status is not known, newborn screening is needed by measurement of ceruloplasmin level in Guthrie dried blood spots. ${ }^{23}$ But a negative blood or urine screening of a newborn does not entirely rule out the disease process and repeat screening should be advised at 2 to 5 years of age. ${ }^{22}$

It is important to note that merely copper chelation therapy does not necessarily assure a favorable pregnancy outcome. Preexisting poor hepatic and renal profile or severe neuropsychiatric illness must be taken into consideration as even a well-chelated pregnancy can turn complicated. ${ }^{21}$

\section{CONCLUSION}

Untreated Wilson disease can lead to many complications and most may have difficulty in conception. Diagnosis and regular antenatal surveillance by a multidisciplinary team result in successful maternal and perinatal outcome. Penicillamine has been effective and found to be safe in treating Wilson disease in our study, but further studies are required.

\section{REFERENCES}

1. Malik A, Khawaja A, Sheikh L. Wilson disease in pregnancy: case series and review of literature. BMC Res Notes 2013 Oct;6:421.

2. Pfeiffer RF. Wilson disease. Semin Neural 2007 Apr;27(2): 123-132.

3. Gibbs K, Walshe JM. A study of the ceruloplasmin concentrations found in 75 patients with Wilson disease, their kinships and various control groups. Q J Med 1979 Jul;48(191):447-463.

4. Hung IH, Suzuki M, Yamaguchi Y, Yuan DS, Klausner RD, Gitlin JD. Biochemical characterization of the Wilson disease protein and functional expression in the yeast Saccharomyces cerevisiae. J Biol Chem 1997 Aug;272(34):21461-21466.

5. Scheinberg, HI.; Sternlieb, I. Neuropathology. In: Smith LH, editor. Wilson's disease. 1st ed. Philadelphia (PA): Saunders; 1984. p. 64-69.

6. Brewer, GJ. Wilson disease: a clinician's guide to recognition, diagnosis, and management. Boston (MA): Kluwer Academic Publishers; 2001. 
7. Mustafa MS, Shamina AH. Five successful deliveries following 9 consecutive spontaneous abortions in a patient with Wilson disease. Aust N Z J Obstet Gynaecol 1998 Aug;38(3): 312-314.

8. Morimoto I, Ninomiya H, Komatsu K, Satho M. Pregnancy and penicillamine treatment in a patient with Wilson disease. Jpn J Med 1986 Feb;25(1):59-62.

9. Scheinberg IH, Sternlieb I. Pregnancy in Penicillamine treated patients with Wilson disease. N Engl J Med 1975 Dec;293: 1300-1302.

10. Oster G, Salgo MP. The copper intrauterine device and its mode of action. N Engl J Med 1968;278:352-359.

11. Sinha S, Taly AB, Prashanth LK, Arunodaya GR, Swamy HS. Successful pregnancies and abortions in symptomatic and asymptomatic Wilson disease. J Neurol Sci 2004 Jan;217(1): 37-40.

12. Haggstrom GD, Hirschowitz BI, Flint A. Long-term penicillamine therapy for Wilson disease. South Med J 1980 Apr;73(4):530-531.

13. Sternlieb I, Scheinberg IH. Penicillamine therapy for hepatolenticular degeneration. JAMA 1964 Sep;189:748-175.

14. Walshe JM. The management of pregnancy in Wilson disease treated with trientine. Q J Med 1986 Jan;58(225):81-87.

15. Dupont $\mathrm{P}$, Irion $\mathrm{O}$, Béguin FÇ. Pregnancy in a patient with treated Wilson disease: a case report. Am J Obstet Gynecol 1990 Nov;163(5):1527-1528.
16. Walshe JM. Wilson disease: the presenting symptoms. Arch Dis Child 1962 Jun;37:253-256.

17. Hoogenraad TU. Paradigm shift in the treatment of Wilson disease: zinc therapy now treatment of choice. Brain Dev 2006 Apr;28(3):141-146.

18. Yuzbasiyan-Gurkan V, Grider A, Nostrant T, Cousins RJ, Brewer GJ. The treatment of Wilson death with zinc: $X$. intestinal metallothionein induction. J Lab Clin Med 1992 Sep;120(3):380-386.

19. Członkowska A, Gromadzka G, Büttner J, Chabik G. Clinical features of hemolysis, elevated liver enzymes, and low platelet count syndrome in undiagnosed Wilson disease: report of two cases. Arch Gynecol Obstet 2010 Jan;281(1):129-134.

20. Theodoridis TD, Zepiridis L, Athanatos D, Dinas K, Tzevelekis F, Bontis JN. Placenta abruption in a woman with Wilson disease: a case report. Cases J 2009 Aug;2:8699.

21. Bhattacharyya SK, Saha SP, Samanta J, Roychowdhuri A. Pregnancy in a woman with Wilson treated with zinc: a case report. Korean J Obstet Gynecol 2012 Mar;55(3):180-182.

22. Roberts EA, Schilsky ML, American Association for Study of Liver Diseases (AASLD). Diagnosis and treatment of Wilson disease: an update. Hepatology 2008 Jun;47(6):2089-2111.

23. Kroll CA, Ferber MJ, Dawson BD, Jacobson RM, Mensink KA, Lorey F, Sherwin J, Cunningham G, Rinaldo P, Matern D, et al. Retrospective determination of ceruloplasmin in newborn screening blood spots of patients with Wilson disease. Mol Genet Metab 2006 Sep-Oct;89(1-2):134-138. 